\title{
Agglutination Effect of Selected Medicinal Plant Leaf Crude Extracts on A-B-O Blood Group
}

\author{
Mohamed Mangondato Solaiman \\ Department of Biology, Mindanao State University-Main Campus, Marawi City, Lanao Del Sur, Philippines \\ Email address: \\ solaimanmohamed39@gmail.com \\ To cite this article: \\ Mohamed Mangondato Solaiman. Agglutination Effect of Selected Medicinal Plant Leaf Crude Extracts on A-B-O Blood Group. American \\ Journal of Plant Biology. Vol. 6, No. 1, 2021, pp. 11-18. doi: 10.11648/j.ajpb.20210601.12
}

Received: December 26, 2020; Accepted: January 25, 2021; Published: February 10, 2021

\begin{abstract}
This study was conducted to test the agglutinating properties of leaf crude extracts of selected plants on human AB-O blood group. The experimental plants used were as follows: kasapi-sapi (Ageratum conyzoides L.), Vicks (Origanum vulgare L.), Sabi (Chenopodium ambrosioides L.), Dunggaw (Bryophylum pinnata L.). The blood types of the 90 blood donors were pre-determined using the commercially available anti-sera A and B. Each blood samples were tested with the four plant leaf crude extracts for the agglutination reaction and were examined under the microscope. Presence of agglutination of red blood cells was marked as positive and absence of such reaction was marked as negative. The result had shown that kasapi-sapi (A. conyzoides L.) and Sabi (C. ambrosioides L.) did not cause agglutination of red blood cells in any of the human blood types. Dunggaw (B. pinnata L.) and Vicks (O. vulgare L.) leaf crude extracts did cause agglutination of the red blood cells from the donors, but, not to a specific blood type. Thus, none of the experimental plants could serve as a substitute for commercially produced anti-sera but could serve as first aid during emergency cases to stop excessive bleeding.
\end{abstract}

Keywords: Agglutination, A-B-O Blood Group, Blood, Coagulation, Medicinal Plants, Anti-sera A and B

\section{Introduction}

Blood as a connective tissue, has multiple functions. It transport oxygen, nutrients, and other solutes to cells. It carries away their secretions including hormones and metabolic wastes. Blood helps stabilize internal $\mathrm{pH}$. It serves as a highway for phagocytic cells that scavenge tissue debris and fight infection. Blood helps equalize body temperature. It does this by carrying excess heat from skeletal muscles and other regions of high metabolic activity to the skin, where heat can be dissipated [4].

The A-B-O blood typing is analyzed on red blood cells (erythrocytes) in one kind of self marker of molecular distinction. Person with one form of the marker are said to have blood type A, and those with another form have blood type B. Many people have both forms of the marker on their red blood cells, they have type AB blood. Other have neither form of the marker, they have blood type O. If you are blood type A, your antibodies neglect A markers but will act against blood type B markers. If you are blood type B, your antibodies neglect $\mathrm{B}$ markers but will act against blood type A marker. If you are blood type $\mathrm{AB}$, your antibodies neglect both forms of the marker, so you can allow donations of blood type A, B, or AB blood. However, if you are blood type $\mathrm{O}$, you have antibodies against both forms of the marker, therefore you are limited to type O donations [4].

The compatibility of blood type is very important in due to the blood transfusion the risk of the donor's blood clumping in the recipient's bloodstream, which is called agglutination. The clumping of the red blood cells can cause serious toxic reactions, often times leading to death in the person receiving the transfusion. Agglutination is an immune system-induced reaction that occurs in the presence of antibodies that form against the donor's red blood cells. In order to mitigate agglutination, the donor and receiver's blood types must be compatible. Blood types are determined by the presence of varied protein molecules, most notably, antigens and antibodies. Antibodies are found in the blood plasma, which is the liquid substrate for the red blood cells, the oxygen-carrying components of the blood. Antigens are found on the surface of each red blood cell. Each individual has varying combinations of these antigens and antibodies. Which combination is present depends largely on heredity. For this reason, many blood transfusions take place between the donor and siblings, 
parents, or other close family members [11].

Coagulation is also referred to clotting is the method by which blood turns from a liquid to a gel. It possibility results in homeostasis, the stoppage of blood loss from a injured vessel, followed by repair. The method of coagulation involves activation, adhesion, and aggregation of platelets along with deposition and maturation of fibrin. Disorders of coagulation are disease that can result in bleeding hemorrhage or bruising or obstructive clotting thrombosis (Lillicrap et al, 2009).

In this study, the A-B-O blood group were subjected to agglutination reaction test using the leaf crude extracts of experimental plants namely: kasapi-sapi (A. conyzoides $L$.), vicks $(O$. vulgare $L$.), sabi ( $C$. ambrosioides $L$.), and dunggaw (B. pinnata $L$.) to determine if any of the leaf crude extracts could be used for blood typing and could be used as first aid to stop bleeding injured tissues.

\section{Review of Related Literature}

\subsection{Blood}

Blood is composed of two major components of blood the liquid part, which is called plasma, and the solid part, which includes the various blood cells and platelets. Plasma contains water, antibodies, clotting factors, nutrients, oxygen, carbon dioxide, ions, triglycerides, vitamins, minerals, etc. The solid portion contains erythrocytes (RBC), leukocytes (WBC), and thrombocytes (platelets). Red blood cells are the cells that can carry oxygen because they have many ironcontaining molecules called hemoglobin that attracts oxygen molecule. White blood cells (WBC) are an essential part of our immunity \& assist fight disease. Platelets are fragments of a specialized cell which are needed for the blood clotting process [13].

\subsection{Blood Types}

There are four blood types in the world such as Type A, Type B, Type AB, and Type O. The different types are caused by different proteins in the plasma. Sometimes people who are injured or who have certain illnesses may need more blood. Transfusion are given to replace lost blood. Blood typing must be done to identify the patients particular blood type. If a wrong type of blood is given during a blood transfusion clotting takes place. Clotting, or clumping of red blood cells blocks the tiny capillaries. Then the normal oxygen delivery system breaks down without oxygen, cell die. Blood banks with a variety of known blood types are set up in hospitals to provide needed blood [3].

\subsection{Blood Transfusion}

Blood Transfusion is the transfer of the blood of one person into the body of another. A transfusion replaces blood or elements of blood in a sick or injured person. A person may lose blood as the result of an accident or a disease. The loss of a little blood is usually not serious. But an adult will faint with the sudden loss of quart or liter of blood. If more blood is lost, death may occur unless individuals receives a transfusion (World Book Encyclopedia, 1995).

Blood transfusion is usually the method of receiving blood products into one's circulation into a vein. It is used for different medical conditions to change lost components of the blood. Early transfusions used whole blood component, but modern medical practice commonly utilizes only components of the blood, such as red blood cells, white blood cells, plasma, clotting factors, and platelets [12].

\subsection{Coagulation}

Coagulation is the process to stop bleeding homeostasis and form blood clots after damage to blood vessels. Essentially, coagulation is clotting of the blood, an extremely important process. How our bodies coagulate blood has been a matter of intensive study, since some people with certain disorder like hemophilia are unable to do so. Understanding when coagulation is more hurtful than harmful, such as when a blood clot causes a stroke, has increased our perception of the value of this method and when it might be needed to capture it. You can describe blood clotting in the simplest terms as a system of several parts that is initiated by the damage of a blood vessel. The first thing that occurs during coagulation is constriction. Constriction decrease the injured blood vessel causing it to move blood at a much slower rate. This turns to less bleeding secondly, platelets, an essential part of blood, assemble at the damage site to form a platelet plug. These platelets tend to be signaled by a release of proteins that give the forward march order for platelets to assemble at the injury site. Yet, the platelet plug is only a temporary fix. More is needed to keep the platelet plug in place [18].

Coagulation is considerably preserved throughout biology; in all mammals, coagulation implicate both platelet and protein coagulation factor component [15]. The Human system has been the most extensively researched and is the best known [16]. Coagulation starts immediately after an injury to the blood vessel has damaged the endothelium lining the vessel. Exposure of blood to the space under the endothelium initiates two processes: changes in platelets, and the exposure of subendothilial tissue factor to plasma Factor VII, which ultimately leads to fibrin formation. Platelets immediately produce a plug at the site of injury; this is called primary homeostasis. Secondary homeostasis occurs simultaneously: Additional coagulation factors or clotting factors beyond Factor VII (listed below) respond in a complex cascade to form fibrin strands, which strengthen the platelet plug [17].

\subsection{Agglutination}

Agglutination is to form a mass of particles. The word agglutination comes from the Latin agglutinate, meaning "to glue. In biology, agglutination refers to the grouping together of particles. This process is essentially as part of the immune system, the response process that an organism utilizes to fight disease. Hemagglutination, the clumping of red blood cells, has special applications in medicine, where it is used to 
identify blood type and look the concentration of infecting viruses or bacteria in the bloodstream [19].

The bacteria or viruses invading the body contain specific components called antigens, which activate an immune sytem to response in the host. White blood cells in the body produce proteins known as antibodies in response to the presence of antigens. The antibodies fix with the antigens through a structural mechanism similar to a key and a lock, and can either neutralize the antigen directly or mark it for destruction by the immune system [19].

Agglutination is one method in which antibodies mark antigens for devastation. Antibodies have at least two sites where an antigen can fix, so they are capable of binding with ore than bacterium or virus. When this happen, the invading particles begin to agglutinate or form clamps, through network of antibodies. The clamps eventually become too large to remain in the solution in the blood stream, and precipitate of solution [20].

The protein substance usually found in foods that binds with glycoproteins and glycolipids on the surface of animal cells generating agglutination. Some lectins induce agglutination of erythrocytes in specific blood groups medical. It also plays a essential role in hormonal response. In lay language, this transforms to very tiny molecules found in foods that selectively cause blood and other body tissues to attach together. It causes the tissues of a person of one blood type to stick together will not definitely have similar effect on a person of a different blood type. (http://www.dadamo.com, accessed on august 15, 2014).

\subsection{Experimental Plants}

1. kasapi-sapi

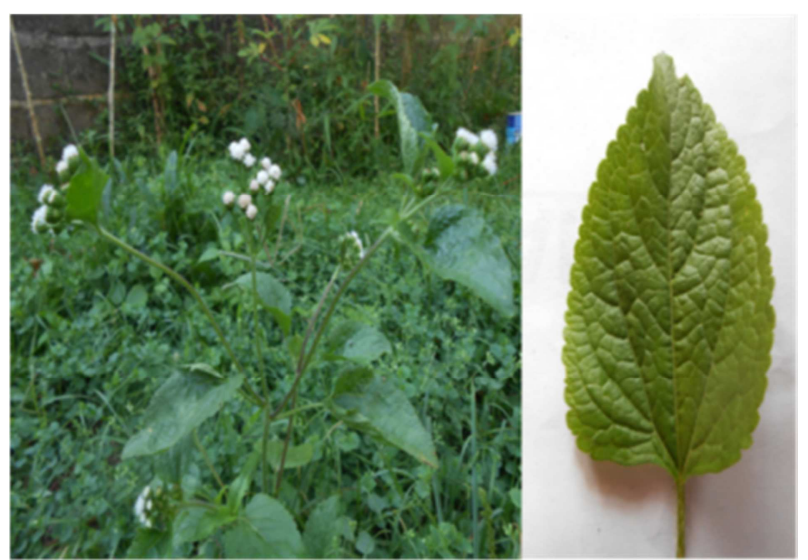

Figure 1. Photograph of Kasapi-sapi (Ageratum conyzoides) Taxonomic Classification.

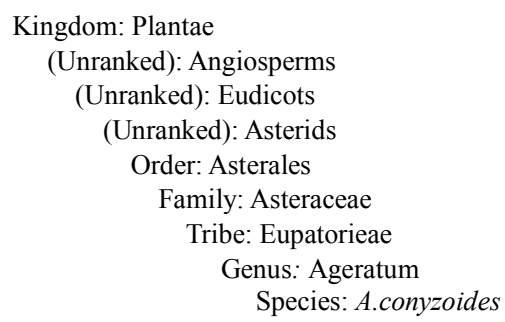

\section{Description:}

A.conyzoides is also known as Kasapi-sapi is usually a vertical, branching, annual herb with shallow and fibrous roots. It may depending upon environmental situation, reach 50-1500 $\mathrm{mm}$ tall at flowering. The stems, which may root where the bases touch the ground, are cylindrical, and become strong and woody with age; nodes and young parts of the stem are covered with short, white hairs. Leaves are opposite, 20-100 mm long, 5-50 mm wide, on hairy petioles $5-75 \mathrm{~mm}$ long, broadly ovate, with a rounded or narrowed acute base and an acute or obtuse or sometimes acuminate tip and toothed margins. Both leaf surfaces are sparsely hairy, rough with prominent veins and when smashed the leaves have a characteristic odor which is reminiscent of the male goat. The branched, terminal or axillary inflorescence bears 4-18 flower heads arranged in showy, flat-topped clusters. Individual flower heads are light blue, white or violet, are carried on 50-150 $\mathrm{mm}$ long peduncles and are $5 \mathrm{~mm}$ across, 4-6 $\mathrm{mm}$ long with 60-75 tubular flowers. The flower head is encircled by two or three rows of oblong bracts which are green with pale or reddish-violet tops. The bracts are 3-5 mm high, outer ones $0.5-1.75 \mathrm{~mm}$ wide, sparsely hairy, evenly toothed in the upper part, with an abruptly acuminate, acute tip. Flowers are 1.5-3 $\mathrm{mm}$ long and scarcely let out above the bracts. The fruit is a ribbed or angled, black achene, $1.25-2 \mathrm{~mm}$ long, roughly hairy, with a pappus of 5 , rarely 6 , rough bristles, white to cream coloured, 1.5-3 $\mathrm{mm}$ long with upward turning spines [22].

\section{Vicks}

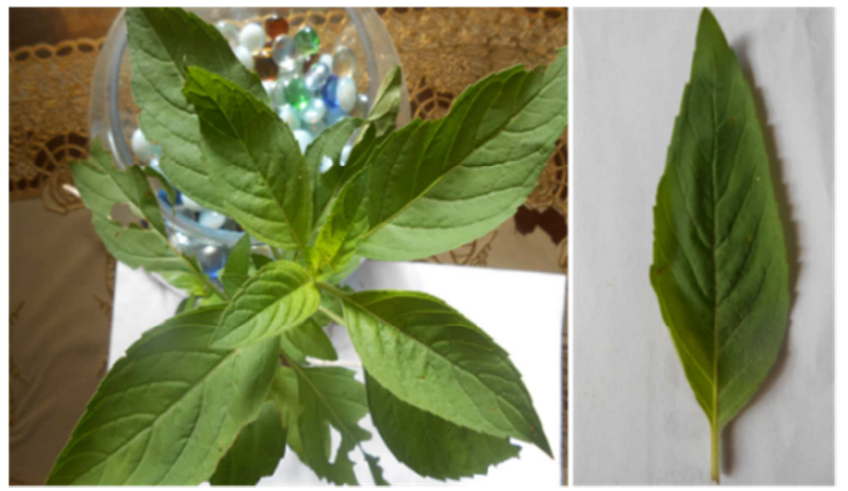

Figure 2. Photograph of Vicks (Origanum vulgare L.) Taxonomic Classification.

Kingdom: Plantae

(Unranked): Angiosperms

(Unranked): Eudicots

(Unranked): Asterids Order: Lamiales Family: Lamiaceae Genus: Origanum Species: $O$. vulgare $L$

Description:

O.vulgare is also known as vicks common species of Origanum, a genus of the mint family Lamiaceae. It is originate to warm-temperate western and southwestern 
Eurasia and the Mediterranean region. Oregano is a perennial herb, flourishing from $20-80 \mathrm{~cm}$ tall, with opposite leaves $1-$ $4 \mathrm{~cm}$ long. Oregano will flourish in a $\mathrm{pH}$ range between 6.0 mildly acidic and 9.0 strongly alkaline with a preferred range between 6.0 and 8.0. The flowers are purple, 3-4 mm long, made in erect spikes. It is also called wild marjoram, and its close relative $O$. majorana is known as sweet marjoram [23].

3. Sabi

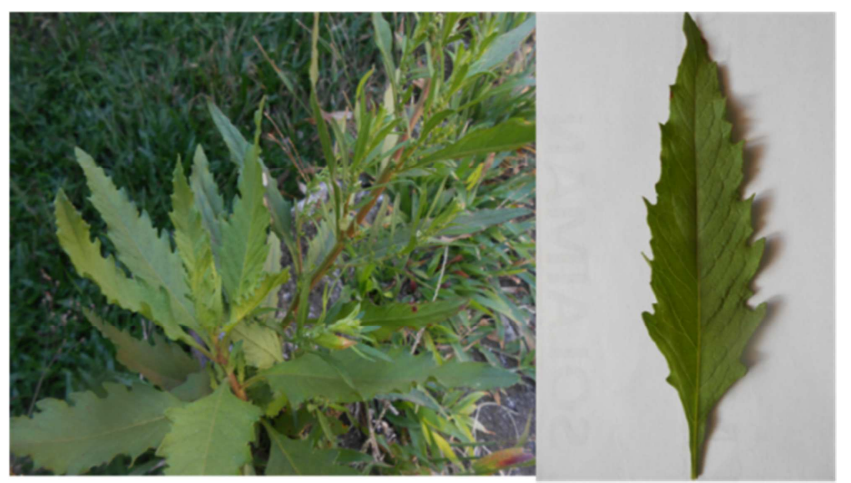

Figure 3. Sabi (Chenopodium ambrosioides L.) Taxonomic Classification.

Kingdom: Plantae

Unranked: Angiosperms

Unranked: Eudicots

Order: Caryophyllales

Family: Amaranthaceae

Subfamily: Chenopodioideae

Genus: Chenopodium

Species: C. ambrosioides $L$

\section{Description:}

C. ambrosioides is also known as sabi is an herb that flourishes to a height of $40 \mathrm{~cm}$. The leaf is oval up to $4 \mathrm{~cm}$ long and $1 \mathrm{~cm}$ wide and toothed. The flower is small and green, and the seed is very small and green when fresh and black when dry. The plant has a very powerful odor. Seeds can be bought through seed catalogues [21].

It is native in Central America, though it has been dispersed to much of the world. It has been utilized as an anthelmintic (medicine for controlling internal parasites) for many years. In the early 1900s it was one of the major anthelmintics used to cure ascarids and hookworms in humans, cats, dogs, horses, and pigs. Usually, oil of chenopodium was used. It was sometimes referred to as Baltimore Oil, because of the large production facility in Baltimore that specialized in extracting the oil from the plant. Chenopodium was replaced with other, more effective and less toxic anthelmintics in the 1940s.

It is still used remedy for worm infections in humans in many countries. In Honduras, as well as other Latin American countries, the whole plant or the leaves are ground and added to water. This mixture is then consumed. In a few areas in Latin America, the plant also used to cure worm infections in livestock [21].

\section{Dunggaw}

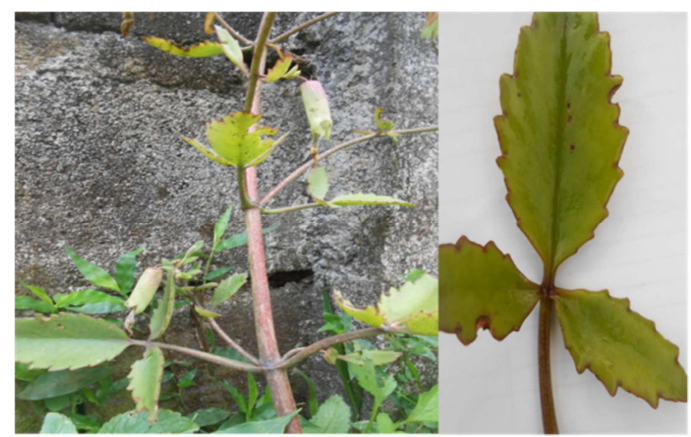

Figure 4. Photograph of Dunggaw (Bryophylum pinnata L.)

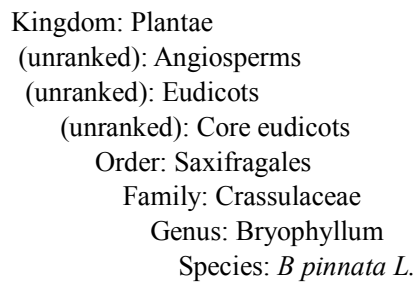

Description:

B. pinnata is also known as dunggaw is an vertical, more or less branched, smooth, succulent herb, 0.4 to 1.4 meters in height. Leaf is simple or pinnately compound, with the leaflets elliptic, usually about 10 centimeters long, thick, succulent, and scalloped margins. Plantlets germinate along the notches of the leaf margins which can grow while still attached to the plant or detached, a fascinating characteristic that earns its name. Flowers are cylindric, and pendulous in a large, terminal panicle. Calyx is tubular, cylindric, inflated, brownish or purplish, 3.5 to 4 centimeters long. Corolla is tubular, about 5 centimeters long, inflated at the base, and then constricted, the exerted parts being reddish or purplish and the lobes tapering to a point. Fruit is a follicle with many seeds. In open settled areas, thickets, dry second-growth forests, sometimes planted, and locally abundant. Prehistoric introduction from tropical Asia or Malaya. Also cultivated, flowering from December to March [24].

It's Phytochemical have produced alkaloids, triterpenes, glycosides, flavonoids, steroids, butadienolides, lipids, and organic acids. Produces arachidic acid, astragalin, behenic acid, beta amyrin, benzenoids, bersaldegenin, beta-sitosterol, bryophollenone, bryophollone, bryophyllin, caffeic acid, ferulic acid, quercetin, steroids, and taraxerol. Phytochemical evaluation of leaf extract gave bryophyllum A, B and C, a potent cytotoxic bufadienolide orthoacetate. Bufadienolide has been declared to be poisonous with digitalis-toxicity type cardiac effects (slowing of heart rate, heart blocks and potentially fatal ventricular arrhythmias. Bryophillin A, a bufadienolide compound, has shown anti-tumor promoting activity. Leaves also reproduce malic acid [24].

\subsection{Related Studies}

In the study using plant leaf crude extracts of avocado $(P$. americana), coffee ( $C$. arabica), fern (A. esculentum), malunggay (M. oleifera), onion (A. cepa), and sakurab (Allium $s p$ ), result showed that the avocado, coffee, and malunggay 
have caused agglutination in all blood types and no agglutination in fern, onion and sakurab in all blood types [5].

In the similar study conducted using the leaf crude extracts of Caesalpina pulcherrima L. (kabalero), Bauhinia purpurea L. (bauhinia), Psidium guajava L. (guava) and Manihot esculenta L. (cassava) were evaluated for their agglutination reaction test on the human A-B-O blood groups. The result showed that kabalero, bauhinia and guava have caused agglutination in all blood types and only the cassava did not agglutinates to all blood types [6].

A study was conducted by Amacol (2013) using the four different plant stem crude extract of balsam (Impatiens balsamina L.), patola (Luffa cylindrical L.), oregano (Coleus aromaticus L.) and four o'clock plant (Mirabilis jalapa L.) for possible presence of agglutination reaction from different human A-B-O blood groups. The result showed that none of stem crude extracts agglutinated on all blood types.

Another study using stem crude extracts was conducted by Pagayocan (2012). The presence of lectin -like substance in the plant stem crude extracts of gotokola, ubi, pala, sakurab, gumamela and periwinkle were evaluated using agglutination reaction test on the human A-B-O blood group. The results showed that all the experimental plants did not cause agglutination on all blood types.

Another study was conducted leaf extracts of selected Maranao medicinal plants to determine their agglutinating property. The result showed that baroraw (Erythrina indica) and talawa-tawa (Euphorbia hirta) caused agglutination to all blood types but cannot be used in determining blood types due to their non-specificity to cause agglutination to a particular blood type. Tangila-lupa (Centella asiatica) also caused agglutination to blood types A, B, and AB except $\mathrm{O}$. Loya pageresen (Zingiber oficinale) caused agglutination to blood types $\mathrm{AB}$ and $\mathrm{O}$ but not to blood type A and B. Ragoma-amo (Bidens pilosa) also caused positive agglutination to blood types $\mathrm{B}$ and $\mathrm{AB}$ but not to blood types $\mathrm{A}$ and $\mathrm{O}$. On the other hand, Kasebang (Physalis angulate) and Kasep-a-nepay (Drynaria cordata) caused no agglutination to all blood types. However, Kasep-a-tao (Oxalis repens) caused agglutination to blood type $\mathrm{O}$ only. Thus, it can be used to determine blood type O. Kodalis-a-riya (Calopogonium mucunoides) caused agglutination to blood type $\mathrm{AB}$ only, thus it can be used to determine blood type AB [7].

Another study on nine seed extract, results showed that betel-nut palm (Areca catechu), and makopa (Syzygium samarangense) seed extracts caused agglutination or clumping of cells of all blood types. On the other hand, alugbati (Basella rubra), black pepper (Piper negrum), fringon (Bauhinia monandra), papaya (Carica papaya), sayote (Sechium edule), squash (Cucurbita maxima) and star apple (Chrysophyllum cainito), seed extracts caused no agglutination of all blood types. Hence, these nine seed extracts are not applicable for blood typing due to their non-specificity to agglutinate the cells of particular blood type [8].

A study using plant seed extracts namely; peanut, corn, lanzones, calamansi, tisa, ampalaya, coffee, guyabano, string bean, and bagiuo bean. Among the seed extract that she used, only ampalaya showed agglutination in blood type $\mathrm{O}$ and there was no agglutination effect on other blood types [9].

A study that determined the lectin and lectin-like substances of ten plant seed extracts through agglutination reaction on the A-B-O blood group system. He used ten plant seeds such as avocado, durian, green peas, jackfruit, marang, mango, red bean, soy bean and white bean seeds. The result showed that only blood type B agglutinated specially when mixed with durian seed extract [10].

\section{Methods and Materials}

\subsection{Collection and Identification of Plant Leaves}

The experimental plants were identified using the book entitled "Maranao Medicinal Plants" (Natangcop et al., 1981). The experimental plants were collected from Kalaw Cawayan, Marantao, Lanao Del Sur during the $20^{\text {th }}$ day of January 2015. Fresh and healthy leaves of the four selective medicinal plants namely: kasapi-sapi (Ageratum conyzoides L.) (Figure 1), vicks (Origanum vulgare L.) (Figure 2), sabi (Chenopodium ambrosioides L.) (Figure 3), and dunggaw (Bryophyum pinnata L.) (Figure 4) were collected and then washed properly with tap water and followed with distilled water to remove the dirty particles of soil.

\subsection{Preparation of Leaf Crude Extracts}

The crude leaf extract from each experimental plant was prepared from 250 grams of each leaf samples. Each leaf samples was macerated and pounded separately using mortar and pestle. The pounded leaves were squeezed using a cheese cloth and were filtered using a filter paper. The crude extracts were placed in pre-labeled sterile vials (Appendix 3).

\subsection{Respondent Profile}

A total of ninety (90) students enrolled for the second semester of the school year 2014-2015 from different colleges of the Mindanao State University served as respondent of the study. The profile of each donor was not considered in this study.

\subsection{Blood Typing}

The blood samples were taken from donors for blood typing using commercially prepared anti-serum A and antiserum B. Blood typing was performed in a series of simple steps. The left or right hand of each donor was cleaned with cotton balls wet with $70 \%$ ethyl alcohol before pricking the fingertip with the blood lancet. Three drops of blood sample were placed at the left and right side of each glass slides. Using toothpick separately, the first drop of blood on the slide was mixed with Anti-serum A, second drop was mixed with the Anti-serum B.

\subsection{Blood Agglutination Reaction Test}

To test the agglutination property of each leaf crude extracts per trial, blood from donors was already pre- 
determined using anti-sera A and B. Few drops of blood sample were obtained from each donors and were placed separate in four glass slides. It was mixed with the four selected leaf crude extracts from each experimental plant using different toothpicks in each. The amount of each leaf crude extracts mixed with the blood samples was estimated to be the same amount of blood sample in each glass slide. The test was done in three trials and each trial had 30 respondents.

\subsection{Gathering of Data}

The results of mixing each leaf crude extracts to the different blood types were recorded and tabulated in Table 1. The different leaf crude extracts-blood sample mixtures were examined under the microscope for agglutination. The presence of red blood cells agglutination were marked as positive $(+)$ and the absence of red blood cells agglutination were marked as negative (-). Photomicrographs of the different leaf crude extracts - blood sample mixture was taken using digital camera (Nikon) and MyPhone 8 megapixels for documentation.

\section{Result and Discussion}

The agglutinating property of: kasapi-sapi (Ageratum conyzoides L.), vicks (Origanum vulgare L.), sabi (Chenopodium ambrosioides L.), and dunggaw (Bryophylum pinnata L.) leaf crude extracts on human blood were evaluated in this study. Furthermore only 25 (27. 77\%) were blood type A, 23 (25.55\%) blood type B, 33 (36.67\%) were blood type $\mathrm{O}$ and $9(10 \%)$ were $\mathrm{AB}$ out of the 90 blood donors. Moreover, the result of the study showed that leaf crude extracts of $B$. pinnata $L$. and $O$. vulgare $L$. caused agglutination or clumping of the red blood cells in blood types $\mathrm{A}, \mathrm{B}, \mathrm{AB}$, and $\mathrm{O}$ while the leaf crude extracts of $C$. ambrosioides $L$. and $A$. conyzoides $L$. did not cause agglutination of the red blood cells in any of the A-B-O blood group as shown in the Tables 1 below.

Table 1. Summary of the agglutination reaction test using different leaf crude extracts on the A-B-O blood System.

\begin{tabular}{lllll}
\hline Blood & Percentage of the blood types & \multicolumn{2}{c}{ LEAF CRUDE EXTRACTS } \\
\cline { 2 - 5 } Type & respondents & Kasapi-sapi & Vicks & Sabi \\
\hline A & $27.77 \%$ & - & + & - \\
B & $25.55 \%$ & - & + & + \\
O & $36.67 \%$ & - & + & + \\
AB & $10 \%$ & + & + \\
\hline
\end{tabular}

Legend:

POSITIVE SIGN $(+)=$ SHOW AGGLUTINATION

NEGATIVE SIGN (-) =NO AGGLUTINATION

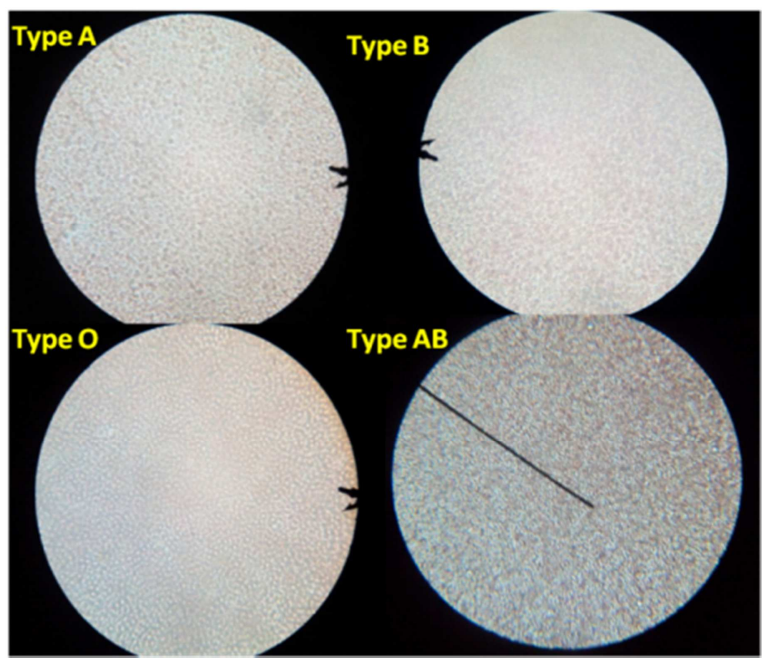

Figure 5. Photomicrograph of the A-B-O blood groups mixed with kasapisapi (Ageratum conyzoides L.) Leaf Crude Extract (100x magnification).

As shown in Figure 5, kasapi-sapi (A. conyzoides) leaf crude extract did not cause agglutination of red blood cells in all blood samples. Such result implied that $A$. conyzoides leaf crude extract may not contain agglutinins that could bind to antigen $\mathrm{A}$ and /or B on the human red blood cells resulting to the absence of agglutination of the blood samples of the A-BO group.

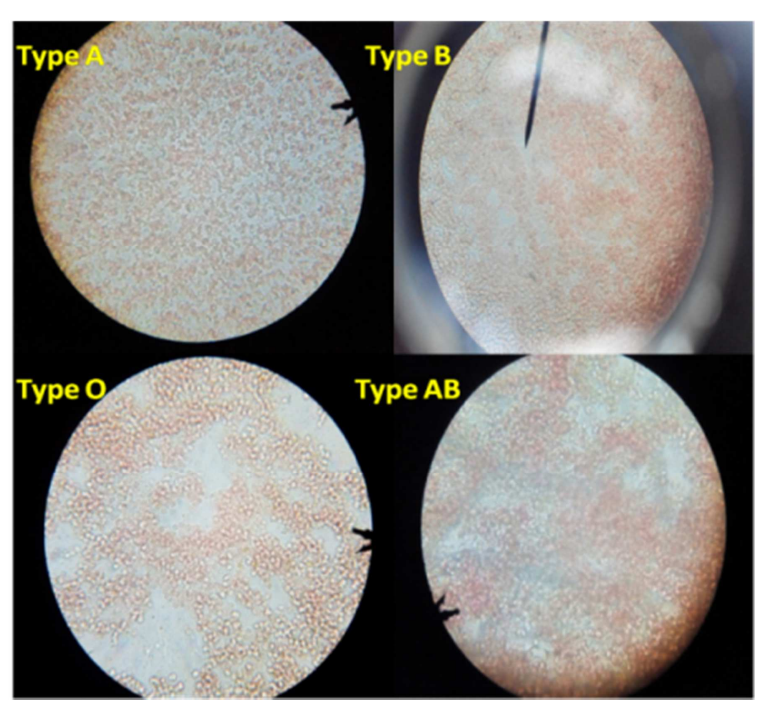

Figure 6. Photomicrograph of the ABO blood groups mixed with vicks (Origanum vulgare L.) Leaf crude extracts (100x magnification).

Figure 6 shows that vicks (O. vulgare) leaf crude extract caused clumping of red blood cells of the all blood types A, $\mathrm{B}, \mathrm{AB}$, and $\mathrm{O}$. It demonstrated that $O$. vulgare leaf crude extract may contain agglutinins that bound to antigens $\mathrm{A}$ and/or B, the human red blood cells resulting to the agglutination of the blood samples of the A-B-O group. 


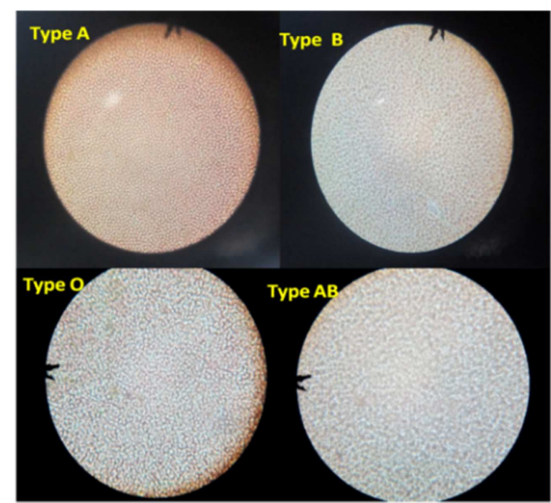

Figure 7. Photomicrograph of the ABO blood groups mixed with sabi (Chenopodium ambrosi- oides L.) Leaf Crude Extract (100x magnification).

Figure 7 shows sabi (C. Ambrosioides) leaf crude extract did not cause agglutination in any of the A-B-O blood group. Such result implied that $C$. ambrosioides leaf crude extract may not contain agglutinins that could bind to antigen A and/ or B on human red blood cells resulting to the absence of agglutination of the blood samples of the A-B-O group.

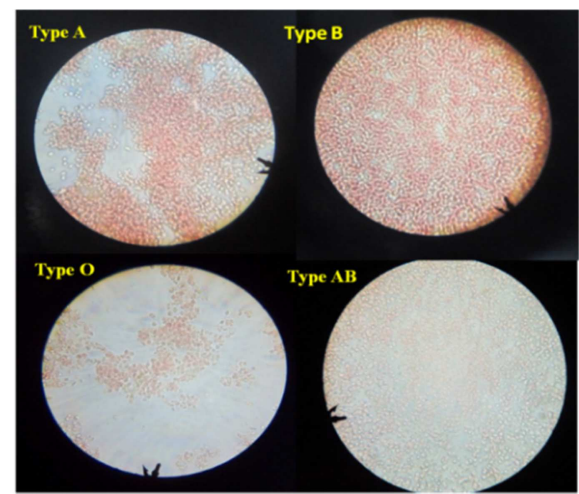

Figure 8. Photomicrograph of the ABO blood groups mixed with dunggaw (Bryophylum pinnata) Leaf Crude Extract (100x magnification).

Figure 8 shows that dunggaw (B. pinnata) leaf crude extract caused clumping of red blood cells in blood types $\mathrm{A}, \mathrm{B}, \mathrm{O}$ and $\mathrm{AB}$. This demonstrates that $B$. pinnata leaf crude extract may contain agglutinins that bound to antigen $\mathrm{A}$ and/ or $\mathrm{B}$ on the human red blood cells resulting to the agglutination of the blood samples of the A-B-O group. The result of this study showed that the agglutination reaction test of the different blood types mixed with the plant leaf crude extracts namely: dunggaw ( $B$. pinnata), and vicks (O. vulgare), caused agglutination reaction in all of the A-B-O blood groups. Leaf crude extracts from these plants may contain agglutinins such as lectins or lectin-like substances. Agglutinins work by clumping on particles causing the particles to change from fluid-like state to a thickened-mass state. However, these plant leaf crude extracts cannot be used for blood typing due to their non-specificity to agglutinate red blood cells of a particular blood type Nevertheless, the leaf crude extracts of dunggaw (B. pinnata) and vicks $(O$. vulgare) could be used as first aid on excessive bleeding of injured parts of body. On other hand, the remaining leaf crude extracts two experimental plants namely: sabi (C. ambrosioides), and Kasapisapi (A. conyzoides) did not cause agglutination on any of the blood types. Leaf crude extracts from those plants may not contain agglutinins such as lectin or lectin-like substances. Lectins have been widely studied from plant seeds; they are also discovered, whereas, other vegetative tissues have low quantities such as root, stem, leaf, bark, etc. Some may hold strong homologous with seed lectins whereas; other may show unusual carbohydrate binding in their red blood cell agglutination feature [2]. Leaves may also contain lectins and in some cases, some plants may even contain lectins mostly in their leaves and not in their seeds. Though, it was already stated that seeds often contain large amounts of lectins. Despite the ubiquitous nature of lectins in plant system, their physiological significance remains speculative [2].

\section{Conclusions and Recommendations}

The study was conducted to test which of the selected plant leaf crude extracts namely kasapi-sapi (Ageratum conyzoides L.), vicks (Origanum vulgare L.), sabi (Chenopodium ambrosioides L.), and dunggaw (Bryophylum pinnata L.) had agglutinins that can cause agglutination on AB-O blood group and which of them could possibly be used as a substitute to the costly produced anti-sera for blood typing and could be used as a first aid excessive bleeding.

Sabi (C. ambrosioides L.) and kasapi-sapi (A. conyzoides $L$.) did not cause agglutination in any of the blood types. Thus, the leaf crude extracts of sabi and kasapi-sapi may not have agglutinins. However, dunggaw ( $B$. pinnata L.), and vicks $(O$. vulgare $L$.) caused agglutination in all blood types. They may contain agglutinins such as lectin or lectin-like substance that caused agglutination in all blood types. In this study none of the leaf crude extracts of the above mentioned experimental plants could be used as a substitute for commercially produced anti-sera A and B because of their non-specificity to cause clumping to a particular blood type. Nevertheless, those leaf crude extracts that caused agglutination of blood samples could be used as first aid during emergency case due to damage area with a excessive bleeding.

\section{Recommendations}

Based on the result of the study, the researcher recommends the following.

1. A similar study on agglutinins of other plants those are available all year round.

2. To test the agglutination reaction test on A-B-O blood group using other plant group such as bryophytes and pteridophytes.

3. To perform histochemical and phytochemical studies on plants that cause agglutination on this study.

4. A similar study using the same experimental plants but different way of extracting medium such as methanol or ethanol extractions.

5. To have awareness drive on the community regarding plants that could be used as first aid to stop bleeding of wounded part of the body. 


\section{Acknowledgements}

The author conveys his sincere and profound gratitude to the individuals who have willingly and helped in the completion of this piece of work; his thesis adviser, Prof. Fatima Natangcop for contributing her knowledge, suggestion, consistent, guidance, support and wholehearted encouragement throughout the conduct of the writing of the manuscript; his panel members, Ms. Carimah M. Usman and Mrs. Merimee D. Caralde for their constrictive criticism, for contributing their knowledge and expertise in thesis writing, meaningful suggestions, and for their support for the improvement of the manuscript; his cousins, aunts and relatives for helping him during the collection of experimental plants; all his donors, classmate, friends, cohort and relatives for their cooperation and support that made this thesis possible; his coagglu cohort, Napoles, Nematods, Sabiha, Jenan, Uno and Oppa; his batch mates, Hafsa, Laila, Hata, Asgar, Azcaya and Ana; his Brothers; Saddam, and Moding for encouragement and became his inspiration to full fill all the trials; his beloved mother Mrs. Sarah M. Solaiman and his father, Engr. Ali M. Solaiman, who support him in terms of financial and emotional aspects and prayed for his success, and whose blessing have always inspired and encourage him; And Above All, the author offers his never ending praises and thanks to the Almighty ALLAH for His divine love, constant guidance, blessing and protection.

\section{References}

[1] Considine, D. (1995). The World Book Encyclopaedia $8^{\text {th }}$ Ed. U.S.A.: World Book-Child craft International Inc.

[2] Konozy, E. H. E, Mulay, R., Faca, V., Ward R., Greene, L., Barriera, M., Sabharwal, S. and Bhide S. (200). Purification, some properties of a D-galactose-bnding Leaf lectin from Erythrima indica and further characterization of seed lectin. Biochimie. Pp. 1035-1043. Retrieved from http://fundherp.frmrp.usp.br/projecto/artigo71.pdf.

[3] La Rue, C. (1986). Basic Biology. U.S.A.: Copyright 1986 by Media Materials, Inc, 1821 Portal Street, Baltimore, Maryland 21224.

[4] Starr, C and Taggart, R. (1995). Biology: The Unity and Diversity of life $7^{\text {th }} E d$. U.S.A: Wadsworth Publishing Company.

[5] Dimapinto, S. (2014). Agglutination Reaction Test on A-B-O Blood Group Using Plant Leaf Crude Extracts. Thesis. Mindanao State University, Marawi City.

[6] Salong, A. (2013) Agglutination Effects of Selected Plant Leaf Crude Extract on A-B-O Blood Group. Thesis. Mindanao State University, Marawi City.

[7] Ali, A. (2010). Test for the Agglutination Effect of Leaf Crude Extracts of Selected Maranao Medicinal Plants on A-B-O Blood Group. Mindanao State University. Marawi City.

[8] Bobong, N. (2008). The effect of selected plant seed extracts on human blood agglutination. Mindanao State University. Marawi City.

[9] Gumaos, S. (1997). A Study of Selected Plant Seed Extracts as Human Blood Agglutination for Blood Determination. Thesis. Mindanao State University, Marawi City.
[10] Alawi, H. (1995). A preliminary study on human blood agglutination using selected plant seed extracts. Thesis. Department of Biology. Mindanao State University, Marawi city.

[11] Blood Type. Retrieved August 15, 2014 from http://www.wisegeek.com/what-is-theimportance-of-bloodtype-for-a-blood-transfusion.html.

[12] Blood Transfusion. Retrieved September 18, 2014 from http://en.wikipedia.org/wiki/Blood_transfusion.

[13] Blood. Retrieved September 18, 2014 from http://www2.pvc.maricopa.edu/tutor/bio/bio160/blood.html

[14] David Lillicrap; Nigel Key; Michael Makris; Denise O'Shaughnessy (2009). Practical Hemostasis and Thrombosis. Wiley-Blackwell. pp. 1-5. ISBN 1-4051-8460-4.

[15] Alan D. Michelson (26 October 2006). Platelets. Academic Press. pp. 3-5. ISBN 978-0-12-369367-9. Retrieved 18 October 2012.

[16] Schmaier, Alvin H.; Lazarus, Hillard M. (2011). Concise guide to hematology. Chichester, West Sussex, UK: WileyBlackwell. p. 91. ISBN 978-1-4051-9666-6.

[17] Furie B, Furie BC (2005). "Thrombus formation in vivo". $J$. Clin. Invest. 115 (12): 3355-62. doi: 10.1172/JCI26987. PMC 1297262. PMID 16322780.

[18] Coagulation. Retrieved on January 1, 2015 from http://en.wikipedia.org/wiki/Coagulation\#cite note-isbn14051-8460-4-1.

[19] Agglutination. Retrieved on September 18, 2014 from http://www.wisegeek.com/what-is-agglutination.htm.

[20] Agglutination. Retrieved on semptember 18, 2014 from http://en.wikipedia.org/wiki/Agglutination_\%28biology\%29\# Agglutination_in_microbiology.

[21] Chenopodium ambrosioides L. Retrieved on February 1, 2015 fromhttp://www.ansci.cornell.edu/plants/medicinal/epazote.ht ml\#description.

[22] Ageratum conyzoides. Retrieved on February 1, 2015 from http://www.cabi.org/isc/datasheet/3572.

[23] Origanum vulgare. Retrieved on February 12015 from http://commons.wikimedia.org/wiki/File:Starr_0801171540_Origanum_vulgare.jpg.

[24] Bryophyllum pinnatum. Retrieved on February 10, 2015 from http://www.stuartxchange.com/Katakataka.html.

\section{Biography}

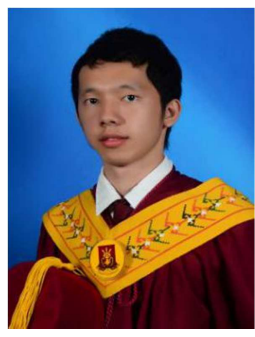

Mohamed Mangondato Solaiman is a 26 years old Faculty members of Mindanao State University - External Units. He earned the Degree Bachelor of Science in Biology and Candidate for Master of Science in Teaching Major in General Science in Mindanao State University -Main Campus Marawi City. He was formerly a instructor in Department of Biology at RC-Al Khwarizmi international College Foundation in Marawi City since 2017. He is a licensed Biology Teacher. His research interests are Microbiology, Botany, Environmental Science and Education. 